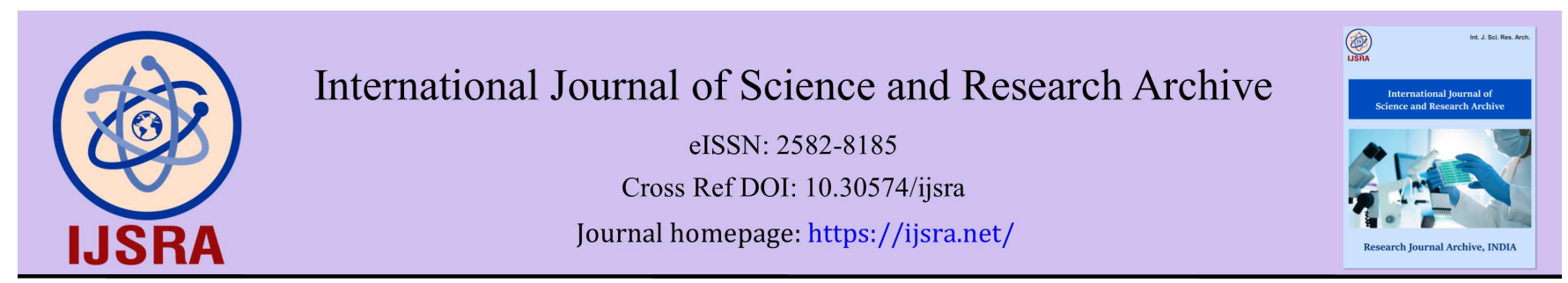

(RESEARCH ARTICLE)

Check for updates

\title{
Maternally requested caesarean delivery: Popularity amongst pregnant women at a South West Nigerian teaching hospital
}

Ramon Sunday Omotayo *, Abayomi Logo, Adetayo Bade-Adefioye, Oluseyi Adewale and Ayomide Emmanuel Sanni

\section{Department of Obstetrics and Gynaecology, University of Medical Sciences Teaching Hospital Complex, Akure Unit, Ondo State, Nigeria.}

International Journal of Science and Research Archive, 2021, 03(01), 019-030

Publication history: Received on 01 June 2021; revised on 04 July 2021; accepted on 08 July 2021

Article DOI: https://doi.org/10.30574/ijsra.2021.3.1.0096

\begin{abstract}
Caesarean Section on maternal request is a planned surgery performed without medical indication, where the wish of the woman compensates for the lack of medical reasons. Preferences for caesarean section are often associated with some factors that may be cultural, economic, religious or social. Some women are said to suffer from tocophobia which is the fear of childbirth and may be a major psychological cause for caesarean section due to maternal request (CSMR). This study explored the popularity of maternally requested caesarean section amongst pregnant women in the Antenatal clinic of University of Medical Sciences Teaching Hospital, Akure.
\end{abstract}

Method: It was a cross-sectional descriptive study.

Results: Willingness to request for caesarean section if not indicated is found to be low with only about $10 \%$ indicating that they can do so. Rather, refusal to undergo caesarean section when medically indicated is found to be relatively high with $43 \%$ of respondents indicating their unwillingness to have caesarean section even if indicated. Fear of adverse occurrence to mother or baby is the major reason for avoiding caesarean section

Conclusion: Maternally requested caesarean section is not popular amongst pregnant women while aversion to indicated caesarean section is high in the study area. There is need for massive education and enlightenment on caesarean section in order to improve its acceptability.

Keywords: Caesarean section; Maternal request; Aversion to caesarean section; Fear of labour

\section{Introduction}

In western countries, caesarean section rates have increased rapidly over the last decade. The reason for this is multi factorial, but relates in part to a rise in medico-legal cases, alongside greater access to health care and the equipment and expertise needed [1]. Many women have morbid aversion towards caesarean section due to numerous nonevidences based socio-cultural reasons but adequate health education and access to antenatal care services can help eliminate cultural beliefs and myths thereby curb the ugly trend [2].

Preferences for caesarean section may often be associated with some factors such as having a history of previous Caesarean Delivery (CD), fear of birth, maternal age, maternal education, socio-economic factors and so on. Having a history of delivery may affect the preference for caesarean in pregnant women [especially in those who have a previous

\footnotetext{
${ }^{*}$ Corresponding author: Ramon Sunday Omotayo

Department of Obstetrics and Gynaecology, University of Medical Sciences Teaching Hospital Complex, Akure Unit, Ondo State Nigeria.
}

Copyright (C) 2021 Author(s) retain the copyright of this article. This article is published under the terms of the Creative Commons Attribution Liscense 4.0. 
history of unpalatable experience of labour pains that was poorly managed or other difficulties with labour previously [3].

In the developed countries, Caesarean section has become well established with ease and safety. The ceasarean section rate worldwide is currently stated to be about 15\% [4]. Indications such as cephalo-pelvic disproportion and fetal distress have been implicated in the rising rate of caesarean section in the tropics. Women's requests for CS have to a great extent, contributed to the escalating rate. Caesarean Section on maternal request is planned surgery performed without medical indication, where the wish of the woman compensates for the lack of medical reasons. The concept of "patient's choice" is well accepted among obstetricians.

Between 6-10\% of women are said to suffer from tocophobia which is the fear of childbirth and is a major psychological cause for Caesarean Section due to Maternal Request (CSMR) [5]. Across Nigeria, 58,000 women die in childbirth every year, giving the country the world's fourth-highest maternal mortality rate. Part of the problem is the country's low caesarean rate: just 2.1\% [8]. Meanwhile, there's just 3 doctors for every 10,000 people in the country [6].

\subsection{Caesarean section rate}

In the global context where caesarean section rates are rising rapidly, Nigerian's numbers stand out. Between 2000 and 2015 caesarean section rates almost doubled across the world. In countries like the Dominican Republic, women now undergo the surgery in up to $50 \%$ of cases. In 2013, a survey in the country revealed general Caesarean section rate of $56 \%$ and even up to $87 \%$ in their private hospitals [7]. In north America, it's $32.6 \%$, in the United Kingdom, 26.2\%. In west Africa, an average of just $4.1 \%$ of births involve a caesarean section and Nigerian's rates is half of that which is $2.1 \%$ according to a secondary analysis of nationally represesntatative 2013 NHDS data [8]. In Ondo state, a 10-year review of data in 2016 revealed fluctuation of Caesarean Section rate between 5\%-20\% [9].

These observations have led to the hypothesis that differences in obstetric practice and the health care system constitute the primary influence in national caesarean section rates [10].

There can be as much as $62.75 \%$ reduction in maternal mortality rate when low-income countries increase their caesarean section rate to WHO recommended levels. [11]. In Nigeria the obstacle to access is especially high in rural areas where roughly $58 \%$ of deliveries take place with unskilled birth attendance. In urban centres with more hospitals, costs and stigma are the primary barriers [12]. Stigma is driven by notions that vaginal birth is aligned with womanhood, whereas caesarean sections are not - a common idea even in countries like the UK. That is even fortified by religion in Nigeria: Christian women hear that giving birth vaginally like a "Hebrew woman" is a sign of strength and competency. This originates from a passage in the Bible, which tells the story of "vigorous" Hebrew women who stoically give birth unattended by midwives [13]. Nigeria is a deeply religious country, and everything is very spiritualised. That mythic ability to give birth vaginally- and unattended -has been upheld as a symbol of maternal virtue in Nigeria [14]. In other countries like the United Kingdom and the United states, the situation may not be as extreme. But women still face stigma for having Caesarean section [15]. Inability of women to take decisions for themselves independently also affects their choice and acceptance of caesarean section. Often, women have limited controls over their own births: one case study of a Nigerian hospital revealed that in $62.9 \%$ of cases, women believed men should be the ones to sign the consent form enabling them to undergo C-section [16]. thus placing the decision firmly in males hands. Whereas, Women should be the primary decision-makers at birth. The limited autonomy of women in developing countries is a major obstacle to improving their reproductive health [17].

About 295,000 women die during and following pregnancy and childbirth in 2017 worldwide. The vast majority of cases (94\%) occurred in low resource settings and most could have been prevented [18]. The global plans to correct this situation have not achieved much improvement. Some of the militating factors identified apart from direct obstetric causes as barriers to achieving this objective include poverty, illiteracy, access difficulties, culture and aversion to caesarean section. In Ondo State, a confidential enquiry into maternal deaths had estimated 253 deaths per 100,000 as published in 2019 [19].

Caesarean section is an important aspect of modern obstetric care and a major tool in the reduction of maternal and perinatal morbidity and mortality. Thus, aversion to caesarean section constitute a very formidable obstacle to save motherhood [20]. However, some pregnant women voluntarily request for caesarean section even when there are no obvious indications for reasons that include previous history of unpalatable experience of labour pains that was poorly managed, previous perinatal deaths or other difficulties with labour previously. It is important to note that caesarean section, despite its numerous advantages, also has its own risks and side effects. 
International Journal of Science and Research Archive, 2021, 03(01), 019-030

It is expedient to investigate the trend of Maternally Requested Caesarean Delivery (MRCD) in an emerging Teaching hospital like the University of Medical Sciences Teaching Hospital (UNIMEDTH), Akure.

\subsection{Aversion for caesarean section}

The major reason given by women for refusing caesarean section was fear of death during surgery [21]. This fear is understandable, given the high rate of maternal deaths associated with caesarean section in sub-Saharan Africa [22]. The paradox is that a significantly higher number of women died in the group that rejected elective caesarian section than in the group that accepted it.

Caesarian section (C/S) is still being perceived as an abnormal means of delivery by many antenatal women in Nigeria. Notwithstanding the undeniable role of caesarian section in successful childbirth and the safety of the procedure in modern times, Nigerian women have developed aversion to caesarian section for various cultural reasons. Women with Previous caesarian delivery reportedly have poor self-esteem and caesarian section are sometimes refused in emergency situations [23].

Adeleye (1981) noted that majority of the procedure (35.1\%) were repeat caesarean section, $25.1 \%$ were for prolonged labour and $30.8 \%$ were primary caesarean section.

The studies that reported the lowest CS preference rate came from Nigeria. The reasons given from these were the complications that followed the procedure and the discriminatory attitudes of others towards them. This finding has confirmed the suspicion that some inappropriate motherhood choices that Nigerian mothers make emanate from superstition and misconceived cultural and religious beliefs.

\subsection{Caesarean section on maternal request (CSMR)}

It has been reported that high education attainment, use of reproductive technology, previous operative deliveries and miscarriages within the obstetric history could be positively correlated with the choice of CSMR in a statistically significant way [24]. Improvements in surgical techniques and improvements in safety have led mothers to think of caesarian delivery as a viable alternative to vaginal delivery even in the absence of any maternal or fetal indication [25].

Therefore, despite reported high aversion for Caesarean Section in this region, there are still incidences of maternal demands for Caesarean Section. In developed countries, while fear of birth, increasing maternal age at marriage and first pregnancy, fear of pelvic floor damage, and genital prolapse in later years are implicated reasons, in developing countries, the view that caesarian section is the surest way to a live birth is believed to be a critical factor underlying their choice [26].

This perspective, however overlooks the fact that a Caesarean Section is a surgical procedure with numerous potential complications for both mother and child. Pregnant women requesting Caesarean Section in the absence of obstetric indications has become a highly debated issue in academic as well as popular literature [27].

The decision whether to accept or refuse a request for Maternally Demanded Caesarean Section (MDCS) presents a moral and ethical dilemma for the obstetrician in choosing between the patient's right to an autonomous decision and the care giver's right to operate in accordance with accepted medical practice [28].

It is argued that vaginal delivery, which is considered the preferred alternative by the ethics of medical practice, is not without risks. So far, there are no randomized controlled trials as yet showing superiority of planned vaginal delivery over planned caesarean section to inform an evidence-based choice [29].

The first study on MDCS published from Nigeria and West Africa was conducted amongst southeastern Nigerian women requesting MDCS between 2003 and 2006. In that study, 4.4\% of all CS deliveries were due to maternal request. The majority of the women had tertiary education, and common reasons for their request were previous infertility and advanced maternal age. None of them had any regrets about their choice of MDCS. In a follow-up study to determine women's opinions on MDCS, prolonged infertility, repeated pregnancy losses, and advanced maternal age at first pregnancy were common reasons for the choice [30]. 


\section{Material and methods}

\subsection{Study site}

The study was carried out at the University of Medical Sciences Teaching Hospital Complex, Akure.

\subsection{Study design}

This study was a descriptive cross-sectional study. This single-center, cross sectional study recruited pregnant women attending ANC. Following approval of the study protocol by the Hospital research and ethics committee, all women fulfilling the recruitment criteria received informative discussion about the nature of the study. Those that agree to enter the study signed a written informed consent.

\subsection{Study population}

The study population consisted of multiparous pregnant women attending the ANC of the University of Medical Sciences Teaching Hospital Complex, Akure. The Teaching hospital is a tertiary health facility with an Obstetrics and Gynaecology department dedicated to the care of pregnant women amongst other things. It is situated around the city center and has about 1500 deliveries every year.

\section{Exclusion and inclusion criteria}

\subsection{Exclusion criteria}

The exclusion criteria include, objection to participate in the study.

\subsection{Inclusion criteria}

Any pregnant woman who has delivered before and attending the antenatal clinic during the period of the study.

\subsection{Information and consent taking}

All eligible women were informed about the study using the patient information sheet and were appropriately counselled. Patients who could not read or write English had their questionnaires interpreted to them. Informed written consent were obtained. All eligible women who gave written consent were recruited for this study

\subsection{Sample size}

The Study is a descriptive study. A total of 252 pregnant women who have had at least 1 previous delivery were randomly selected by choosing alternate patients as they arrived and over a period of 3 months.

\subsection{Data collection: Instrument}

A simple structured questionnaire was used as instrument for collecting data. It was written in plain English language and provision for interpretation made for those that cannot understand or read English.

\subsection{Data presentation and management}

Data was processed by feeding the information into SPSS and then analysed using the SPSS version 20. Proportions were calculated using percentages.

\section{Results}

Majority of respondents 142 (56.3\%) were in the age group 30-39years. Only 18 (7.1\%) were teenagers. Table 1. Only $6(2.4 \%)$ of the respondents were single, all the others $246(97.4 \%)$ were married. Over ninety percent (92.1\%) were of the Yoruba ethnicity, $14(5.6 \%)$ of the respondents were Igbo while $2(0.8 \%)$ were Hausa. Table 1 . Majority of the respondents 228 (90.5\%) were Christians and 20 (7.9\%) were Muslims, Table 1. One hundred and sixty-six respondents, (65.9\%) were graduates, 24 (9.5\%) had other post-secondary education. Only $2(0.8 \%)$ of the respondents had no any formal education. Table 1 . Half of the respondents were into business for daily living while 26 (10.3\%) were full housewives. Table 1 . Analysis of the social class status of the respondents revealed $98(38.9 \%)$ were in social class $3,84(33.3 \%)$ were in social class 2, $34(13.5 \%)$ in social class 1 and only $6(2.4 \%)$ in social class 5 . Table 1. 
Table 1 Socio-demographic biodata

\begin{tabular}{|c|c|c|}
\hline Variable & Frequency & Percentage (\%) \\
\hline \multicolumn{3}{|l|}{ Age group (Years) } \\
\hline$<20$ & 18 & 7.1 \\
\hline $20-29$ & 72 & 28.6 \\
\hline $30-39$ & 142 & 56.3 \\
\hline $40-49$ & 20 & 7.9 \\
\hline Total & 252 & 100.0 \\
\hline \multicolumn{3}{|l|}{ Marital Status } \\
\hline Single & 6 & 2.4 \\
\hline Married & 246 & 97.4 \\
\hline Total & 252 & 100.0 \\
\hline \multicolumn{3}{|l|}{ Ethnicity } \\
\hline Yoruba & 232 & 92.1 \\
\hline Igbo & 14 & 5.6 \\
\hline Hausa & 2 & 0.8 \\
\hline Others & 4 & 1.6 \\
\hline Total & 252 & 100.0 \\
\hline \multicolumn{3}{|l|}{ Religion } \\
\hline Islam & 20 & 7.9 \\
\hline Christianity & 228 & 90.5 \\
\hline Others & 4 & 1.6 \\
\hline Total & 252 & 100.0 \\
\hline \multicolumn{3}{|l|}{ Education } \\
\hline Primary & 16 & 6.3 \\
\hline Secondary & 44 & 17.5 \\
\hline Post-Secondary & 24 & 9.5 \\
\hline Graduate & 166 & 65.9 \\
\hline No formal Education & 2 & 0.8 \\
\hline Total & 252 & 100.0 \\
\hline \multicolumn{3}{|l|}{ Occupation } \\
\hline Full House wife & 26 & 10.3 \\
\hline Artisan & 36 & 14.3 \\
\hline Business & 126 & 50.0 \\
\hline Civil Servants & 60 & 23.0 \\
\hline Students & 4 & 1.6 \\
\hline Total & 252 & 100.0 \\
\hline \multicolumn{3}{|l|}{ Social Class } \\
\hline Class 1 & 34 & 13.5 \\
\hline Class 2 & 84 & 33.3 \\
\hline Class 3 & 98 & 38.9 \\
\hline Class 4 & 30 & 11.9 \\
\hline Class 5 & 6 & 2.4 \\
\hline Total & 252 & 100.0 \\
\hline
\end{tabular}

About a half of the respondents $128(50.8 \%)$ were at gestational age of $17-32$ weeks and $76(30.2 \%)$ were at gestational age of 30-40weeks. Table 2. Majority of the respondents 154 (61.1\%) had their last delivery at 37-40weeks, Table 2. The last delivery of respondents produced live healthy babies in 224 (88.9\%) of them, 22 (8.7\%) had dead babies and $6(2.4 \%)$ had babies that suffered injuries needing admission. Table 2. One-hundred and fourteen (45.2\%) of the 
respondents desire to have 3 children to complete their family size while 92 (36.5\%) needed 4 children. Only 18 (7.2\%) desire more than 4 children. Table 2.

Table 2 Obstetrics information of respondents

\begin{tabular}{|c|c|c|}
\hline Variable & Frequency & Percentage (\%) \\
\hline \multicolumn{3}{|l|}{ Gestational Age (Weeks) } \\
\hline$<8$ & 4 & 1.6 \\
\hline $8-16$ & 44 & 17.5 \\
\hline $17-32$ & 128 & 50.8 \\
\hline $33-40$ & 76 & 30.2 \\
\hline Total & 252 & 100.0 \\
\hline \multicolumn{3}{|c|}{ Gestational Age of Last Delivery (Weeks) } \\
\hline$<34$ & 16 & 6.3 \\
\hline $34-36$ & 30 & 11.9 \\
\hline $37-40$ & 154 & 61.1 \\
\hline$>40$ & 52 & 20.6 \\
\hline Total & 252 & 100.0 \\
\hline \multicolumn{3}{|l|}{ Last Delivery outcome } \\
\hline Baby Survived & 224 & 88.9 \\
\hline Baby died & 22 & 8.7 \\
\hline Baby Suffered injury/admitted & 6 & 2.4 \\
\hline Total & 252 & 100.0 \\
\hline \multicolumn{3}{|l|}{ Number of children desired } \\
\hline 2 & 24 & 9.5 \\
\hline 3 & 114 & 45.2 \\
\hline 4 & 92 & 36.5 \\
\hline 5 & 12 & 4.8 \\
\hline 6 & 6 & 2.4 \\
\hline Unsure & 4 & 1.6 \\
\hline Total & 252 & 100.0 \\
\hline
\end{tabular}

Only $66(26.2 \%)$ of respondents have had caesarean section before. Table 3 . The indications for the previous caesarean section include prolonged labour 17 (25.8\%), obstructed labour 10 (15.2\%), fetal distress 10 (15.2\%), fetal macrosomia $10(15.2 \%)$. Table 3. In $40(60.6 \%)$, the patients themselves signed the consent for their surgeries while it was the husband that signed consent in $24(36.4 \%)$, only $2(3.0 \%)$ had consent signed by their other relatives. Table 3.

Only $18(7.1 \%)$ of the respondents believe caesarean section is not safe while majority, $170(67.5 \%)$ believe that caesarean section is safe. Table 4. Fifty-four (21.4\%) were of the opinion that caesarean section done can have effect on next delivery process, 120 (47.6\%) don't believe so and 78 (31.0\%) were unsure. Table 4. Majority of the respondents $208(82.5 \%)$ said children delivered by caesarean section are normal babies while $12(4.8 \%)$ said they are not normal babies. Table 4 .

When asked if they will accept to have caesarean section if indicated in next delivery, $113(53.2 \%)$ respondents will accept while $110(43.7 \%)$ will not accept. Table 5. Reasons for not accepting caesarean section in next delivery even if 
indicated include fear of death from procedure (23.0\%), cost of procedure (14.3\%), fear of discrimination (6.3\%), fear of husbands' rejection $(3.2 \%)$.

Table 3 Respondents with previous caesarean section

\begin{tabular}{|c|c|c|}
\hline Variable & Frequency & $\begin{array}{l}\text { Percentage } \\
(\%)\end{array}$ \\
\hline \multicolumn{3}{|l|}{ Previous Caesarean Section } \\
\hline Yes & 66 & 26.2 \\
\hline No & 186 & 73.8 \\
\hline Total & 252 & 100.0 \\
\hline \multicolumn{3}{|c|}{ Indication for last caesarean section } \\
\hline Prolonged labour & 17 & 25.8 \\
\hline Obstructed Labour & 10 & 15.2 \\
\hline Hypertensive disorder & 3 & 4.5 \\
\hline Other Medical Conditions & 4 & 6.1 \\
\hline Fetal distress & 10 & 15.2 \\
\hline Fetal Macrosomia & 10 & 15.2 \\
\hline Small Pelvis & 4 & 6.1 \\
\hline 2 Previous CS & 2 & 3.0 \\
\hline Breech Presentation & 2 & 3.0 \\
\hline Multiple babies & 2 & 3.0 \\
\hline Ectopic pregnancy & 2 & 3.0 \\
\hline Total & 66 & 100.0 \\
\hline \multicolumn{3}{|l|}{ First to Consent at Last CS } \\
\hline Myself & 40 & 60.46 \\
\hline My husband & 24 & 36.4 \\
\hline Relatives & 2 & 3.0 \\
\hline Total & 66 & 100.0 \\
\hline
\end{tabular}

Values given are absolute number of respondents with the corresponding percentages of total respondents for the parameter

Table 4 Respondents view of caesarean section (cs)

\begin{tabular}{|c|c|c|}
\hline Question/Response & Frequency & $\begin{array}{l}\text { Percentage } \\
(\%)\end{array}$ \\
\hline \multicolumn{3}{|c|}{ Is caesarean section safe } \\
\hline Yes & 170 & 67.5 \\
\hline No & 18 & 7.1 \\
\hline Unsure & 64 & 25.4 \\
\hline Total & 252 & 100.0 \\
\hline \multicolumn{3}{|c|}{ Can CS have effect on subsequent delivery } \\
\hline Yes & 54 & 21.4 \\
\hline No & 120 & 47.6 \\
\hline Unsure & 78 & 31.0 \\
\hline Total & 252 & 100.0 \\
\hline \multicolumn{3}{|c|}{ Are CS children's normal babies } \\
\hline Yes & 208 & 82.5 \\
\hline No & 12 & 4.8 \\
\hline Unsure & 32 & 12.7 \\
\hline Total & 252 & 100.0 \\
\hline
\end{tabular}

Values given are absolute number of respondents with the corresponding percentages 
Table 5. Majority of the respondents 222 (88.1\%) said they will not request for caesarean section on their own while 26 $(10.3 \%)$ said they can request for caesarean section to deliver their babies. Table 5 . Reasons respondents gave for their willingness to request for caesarean section for delivery of their babies even if not indicated include believe that caesarean section guarantees babies safety more in 7 (26.9\%) of those willing to request, to avoid the type of pain experienced at last labour in $14(53.8 \%)$ of those willing to request, desire to keep genital tract intact in $4(15.4 \%)$ of those willing to request and to avoid the fetal death suffered at last labour in $1(3.9 \%)$ of those willing to request. Table 5. Seventy-six respondents (30.2\%) of the respondents said they habour fear of unpleasant happening of labour while $176(69.8 \%)$ said they don't have any fear of unpleasant happenings of labour. Table 5. More than half 140 (55.6\%) of the respondents believe that they have to wait for their husbands to sign consent in case they need caesarean section while $110(43.7 \%)$ don't believe that they have to wait for their husbands to sign consent.

Table 5 Factors determining maternal request for caesarean section

\begin{tabular}{|c|c|c|}
\hline Variable & Frequency & Percentage \\
\hline \multicolumn{3}{|l|}{ Will you accept indicated CS } \\
\hline Yes & 134 & 53.2 \\
\hline No & 110 & 43.7 \\
\hline Unsure & 8 & 3.2 \\
\hline Total & 252 & 100.0 \\
\hline \multicolumn{3}{|l|}{ Why not want Cs next delivery } \\
\hline Fear of death & 58 & 23.0 \\
\hline Cost & 36 & 14.3 \\
\hline Fear of discrimination & 16 & 6.3 \\
\hline Fear of husband's rejection & 8 & 3.2 \\
\hline Total & 134 & 100.0 \\
\hline \multicolumn{3}{|c|}{ Will you request for CS next delivery if not indicated } \\
\hline Yes & 26 & 10.3 \\
\hline No & 222 & 88.1 \\
\hline Unsure & 4 & 1.6 \\
\hline Total & 252 & 100.0 \\
\hline \multicolumn{3}{|c|}{ Why request for CS when not indicated } \\
\hline For baby safety & 7 & 26.9 \\
\hline For the pain of last delivery & 14 & 53.8 \\
\hline To keep genital tract intact & 4 & 15.4 \\
\hline $\begin{array}{c}\text { Because baby was lost at last } \\
\text { delivery }\end{array}$ & 1 & 3.9 \\
\hline Total & 26 & 100 \\
\hline \multicolumn{3}{|c|}{ Do you have fear of unpleasant happening in labour } \\
\hline Yes & 76 & 30.2 \\
\hline No & 176 & 69.8 \\
\hline
\end{tabular}




\begin{tabular}{|c|c|c|}
\hline Total & 252 & 100.0 \\
\hline \multicolumn{3}{|c|}{ Will you wait till your husband comes to sign consent if you do CS } \\
\hline Yes & 140 & 55.6 \\
\hline No & 110 & 43.7 \\
\hline Unsure & 2 & 0.8 \\
\hline Total & 252 & 100.0 \\
\hline
\end{tabular}

\section{Discussion}

Majority of respondents 142 (56.3\%) were in the age group 30-39years, only 18 (7.1\%) were teenagers. Majority of the respondents, $90.5 \%$ were Christians probably because the study was done in the south west of Nigeria that are predominantly Christians. Previous publications have earlier revealed large followership of Christianity in the south of Nigeria [31]. Social class Tahmina Begum et al had earlier opined that probability of C-section delivery increased with improved socioeconomic status [32]. Majority of the respondents had their last delivery at $37-40 \mathrm{week}, 18.2 \%$ had preterm delivery. This is similar to $5-25 \%$ quoted percentagies of preterm births in other studies from Nigeria and America. $[33,34,35]$.

Prolonged labour was the commonest indication 17 (25.8\%), for the previous caesarean sections that respondents with previous caesarean sections have had. While the most common indication for caesarean section generally is previous caesarean section,[36]. prolonged labour due to labour dystocia can be a prominent indication when primary caesarean section is frequent [37].

In the majority (60.6\%) of those that had Caesarean section, the patients themselves were the ones that signed consent for surgery and husbands signed in $34.6 \%$. this is similar to an earlier finding by Ogunbode that $64.0 \%$ of patients sign consent for caesarean section themselves while 28.3\%are signed by husbands. [38].

In the majority (60.6\%) of those that had caesarean section, the patients themselves signed the consent for surgery and husbands signed in $34.6 \%$. this is similar to the findings by Ogunbode in another south west Nigerian study that and $64.0 \%$ of consents for caesarean section are signed by the patients themselves $28.3 \%$ are signed by husbands [38]. Another survey of pregnant women in south east Nigeria revealed that majority of the women will accept to have caesarean section only if their husbands allow. [39]. This study showed that there are still some women (4.8\%) that belief children delivered by caesarean section are not normal babies. This may be due to various myths associated with caesarean section and the high premium placed on natural vaginal delivery especially in this part of the world. 39 However there are now new approaches to doing caesarean section called 'gentle caesarean section' where scenario similar to that of vaginal delivery room is replicated in the operation room including allowing husband or relatives to be present, placing baby on the chest of the mother immediately after delivery with the mother holding the baby and even initiating breastfeeding [40].

More than $40 \%$ of respondents said they are not willing to have caesarean section next delivery even if indicated. This high percentage may be due to the fact that the question was asked at the ANC and not at the actual point of decision for cs where the indication is staring the patient in the face. Prominent among reasons given by respondents for refusing indicated caesarean section include fear of death from the procedure, cost of procedure, fear of discrimination and family rejection. An earlier study by Deshpande and Oxford had listed fear of death, fear of postoperative pain and harm to both mother and baby, concerns of operation cost and hospital fees as part of reasons a woman may refuse physician recommended caesarean section. [41]. some Arab cultures even perceive caesarean section as a form of mutilation [42]. Only a very small percentage of the respondents $(10.3 \%)$ said that they can request for caesarean section in their next delivery even if not indicated citing reasons that include their belief that cs guarantees safety of baby, to avoid type of labour pains experienced in the past, to avoid recurrence of fetal loss suffered in the past and the desire to keep genital tract intact. About $30.2 \%$ of the respondents expressed fear about labour and events around it. In a study that examined childbirth-related fears among women of differing parity and found out that women indeed expressed fears about childbirth with $50 \%$ being fears about childs health, $40 \%$ being fears about pain and $12 \%$ fears about possible interventions [43]. 


\section{Conclusion}

Caesarean section on maternal request is not popular amongst pregnant women in the study population with majority of the respondents (88.1\%) said they will not request for caesarean section on their own while up to $43.7 \%$ will not accept caesarean section even if indicated. This shows significant aversion to caesarean section. There is need for massive education and enlightenment on caesarean section in order to improve its acceptability.

\section{Compliance with ethical standards}

\section{Acknowledgments}

The research was entirely funded by the researcher who has no conflict of interest.

\section{Disclosure of conflict of interest}

No conflict of interest.

\section{Statement of informed consent}

Informed written consent were obtained from all individual participants included in the study.

\section{References}

[1] Ugwu EOV, Obioha KCE, Okezie OA, Ugwu AO. Afive year Survey of Caesarean section Delivery at a Nigerian Tertiary Hospital. Ann Med Health Sci Res. 2011; 1(1): 77-83.

[2] Lawani LO, Igboke FN, Ukaegbe CI, Anozie OB, Iyoke CA, Onu FA, Agbata TA, Asiegbu O. Perception and Sociocultural barriers to the acceptance of caesarean deliveries in a tertiary Hospital in Abakaliki, South East Nigeria. International Journal of Womens Health and Reproduction Sciences. .

[3] Farahani SM, Malekzadegan A, Mohammadi R, Hosseini F. Effects of the one to one midwifery care during labour on modes of delivery. Iran journal of Nursing. 2005; 18: 71-82.

[4] Betran AP, Merialdi M, Lauer JA, Bing-Shun W. Rates of caesarean section: Analysis of global, regional and national estimates. Paediatric and Perinatal Epidemiology. 2007; 21(2): 98-113.

[5] Wiklund I, Edman G, Ryding EL Andolf E. Expectations and experiences of childbirth in primiparae with caesarean section. BJOG. 2008; 115: 324-31.

[6] Lar-Ndam N, Madaki J, Pitmang L, Audu M, Salihu D, GYang M. Burnout among primary care physicians in JosPlateau, north-central Nigeria. Niger J Fam Pract. 2015; 6: 11-18.

[7] McLennan JD. Caesarean section rates in the Dominican Republic. Latin American Research Centre. University of Calgary. July 2015.

[8] Adewuyi EO, Auta A, Khanal V, Tapshak SJ, Zhao Y. Caesarean delivery in Nigeria: prevalence and associated factors- a population based cross sectional study. BMJ open. 2019; 9: e027273.

[9] Adejumo AO, Suleiman EA, Okagbue HI, Oguntunde PE, Odetunmibi OA. Quantitative evaluation of pregnant womrn delivery status records in Akure, Nigeria. Data in brief. 2018; 16: 127-134.

[10] Cnattingius R, Cnattingius S, Notzon F. Obstacles to reducing caesarean rates in a low-caesarean setting.Obstetrics Gynaecology. 1998; 92: 501-506.

[11] Thomas S, Maedows J, Mcqueen K. Access to caesarean section will reduce maternal mortality in low income countries: A mathematical model. World Journal of Surgery. 2016; 40(7).

[12] Ugwu NU, de kok B, Socio-cultural factors, gender roles and religious ideologies contributing to caesarean section refusal in Nigeria. Reproductive Health. 2015; 12 : 70.

[13] Gruber MI. Hebrew women in Egypt: Bible. Jewish womens achive; encyclopedia. Brookline. 2020.

[14] Gunn JKL, Ehiri JE, Jacobs ET, Ernst KC, Pettygrove S, Centre KE, et al. Prevalence of caesarean sectionin Enugu, southeast Nigeria: Analysis of data from the Healthy Beginning Initiative. 2017; 12(3): e0174369. 
[15] Tuteur A. the C-Section problem Nobody Talks about. Body.2016. United States of America.

[16] Bako B, Umar NI. Informed consent practices and its implications for emergency obstetrics care in Azare, NorthEastern Nigeria.Ann Med Health Sci Res. 2011; 1(2): 149-157.

[17] Mumtaz Z, Salway S. understanding gendered influences on women's reproductive health in Pakistan: moving beyond the autonomy paradigm. Soc Sci Med. 2009; 68(7): 1349-56.

[18] Trends in maternal mortality: 2000-2017: estimates by WHO, UNICEF, UNFPA, World Bank Group and the United Nations Population Division. Geneva.; World Health Organisation. 2019.

[19] Oyeneyin L, Van den Akker T, Durojaiye 0 et al. Confidential enquiry into maternal deaths in Ondo State Nigeriaa comparative analysis. BMC Pragnancy Childbirth. 2019; 19: 514.

[20] Ezechi OC, Fasubaa OB, Dare FO. Socio Economic Barriers to safe motherhood among booked patients in rural Nigeria communittees. J Obstet Gynecol. 2000; 20(1): 32-4.

[21] Dumont A, Bernis L, Bouvier-olle M, Breart G. for the MOMA study group. Caesarian section rate for maternal indication in sub-Saharan Africa: a systematic review. Lancet. 2001; 358(9290): 1328-1333.

[22] Ozumba BC, Anya SE. Maternal deaths associated with caesarian section in Enugu, Nigeria. Int J Gynecol Obset 2002; 76: 307-9.

[23] Loto OM, Adewuya AO, Ajanifuja OK, Orji EO, Owolabi AT, Oguniyi SO. The effect of caesarian secton on selfesteem among primiparous women in South-eastern Nigeria:a case-control study.J Matern fetal Neonatal Med. 2009; 22[9].: 765-769.

[24] Gilbert A, Benjamin A, Abenhaim HA. Does education level influence the decision to undergo elective repeat caesarean section among women with a previous caesarean section?. Journal of Obstetrics and Gynaecology Canada. 2010; 32(10): 942-947.

[25] Dahlgren LS, Von Dadelszen P, Christilaw J, Janssen PA, Lisonkova S, Marquette GP, Liston RM. Caesarian section on maternal request: Risks and benefits in healthy nulliparious women and their infants. J. Obset. Gynaecol. Can. $2009 ; 31: 808-817$.

[26] Chigbu CO, Ezeome IV, Iloabachie GC. Caesarian section on request in a developing country. Int J Gynecol Obstet. 2007; 96(1): 54-56.

[27] Homelgren CM. Uterine rupture associated with VBAC. Clin. Obstet. Gynecol. 2012; 55: 978-987.

[28] American College of Obstetricians and Gynaecologists. ACOG Committee Opinion: Surgery and patient Choice. Number 395. Obstet Gynaecol. 2008; 111(1): 243-247.

[29] National Institutes of health. Caesarian delivery on maternal request: NIH consensus and state-of-the-science conference statements. 2006.

[30] Chigbu CO, Ezenyeaku CC. Women's opinions and experiences with induction of labour and caesarian delivery on request in south eastern Nigeria. Int J Gynaecol Obstet. 2008; 103(2): 158-161.

[31] Andrew McKinnon. Christians, Muslims and traditional worshippers in Nigeria: estimating the relative proportions from eleven nationally representative social surveys. Review of religious research. 2021.

[32] Begum T, Rahman A, Anwar I. Indication and determinants of caesarean section delivery: Evidence from a population-based study in Matlab, Bangladesh. PLoS One. 2017; 12(11): e0188074.

[33] Demissie K, Rhoads GG, Ananth CV et al. Trends in preterm birth and neonatal mortality among blacks and white in the United State of America from 1989 to 1997. Am J Epidemiol. 2001; 154: 307-15.

[34] Ezechukwu CC, Uguchukwu EF, Chukwuka JO. Risk factors for neonatal mortality in a regional tertiary hospital in Nigeria. Nig J Clin Pract. 2004; 7: 50-2.

[35] Steer P. The epidiemiology of preterm labour. Br J Obstet Gynaecol. 2005; 112: 1-3.

[36] Akadri AA, Odelola OI. A six year reviewof caesarean section at Olabisi Onabanjo University Teaching Hospital, Sagamu, South West Nigeria. Nigerian Medical Practitioner. 2017; 71(3-4).

[37] American College of Obstetrics and Gynaecology and Society of Maternal-Fetal Medicine. Safe prevention of primary caesarean delivery. Obstetrics care concensus No 1, ACOG. 2014; 123: 693-711. 
[38] Ogunbode 00, Oketona OT, Bello FA. Informed consent for caesarean section at a Nigerisn University Teaching Hospital; patients perspective. Trop J Obstet Gynaecol. 2015; 32 (1).

[39] Ezeoma IV, Ezugworie JO, Udealor PO. Beliefs, perceptions and views of pregnant women about caesarean section and reproductive health decision-making in a specialist health facility in Enugu, south east Nigeria. Niger J Clin Pract. Apr 2018; 21(4): 423-428.

[40] Ashley M, Rev. by Nwadike VR. Planning for a gentle caesarean birth.

[41] Deshpande NA, Oxford CM. Management of pregnant patients who refuse medically indicated caesarean delivery. Rev Obstet Gynaecol. 2012; 5(3-4): e144 e150.

[42] Lipson JD, Dibble SL, Minarik PA. Culture and Nursing care:A pocket guide. San Franscisco CA: University of California San Franscisco. 1996.

[43] Geissbuhler V, Eberhard J. Fear of Childbirth during pregnancy: A study of more than 8000 pregnant women. Journal of Psychosomatic Obstetrics \& Gynecology. 2003; 23(4): 229-35.

\section{Author's Short Biography}

\begin{tabular}{|c|c|}
\hline & $\begin{array}{l}\text { Dr Omotayo Ramon Sunday attended School of Science, Ile-Ife, Osun State 1991-1994 for } \\
\text { his Senior Secondary School certificate. Proceeded to Federal Polytechnic Ede, Osun State } \\
\text { 1996-1998 for the Ordinary National Diploma (OND) in Science Laboratory Technology. } \\
\text { Attended Obafemi Awolowo University, Ile- Ife Osun State from 1999-2007 where he } \\
\text { obtained Bachelor of Medicine, Bachelor of Surgery (MBChB). He did residency program in } \\
\text { obstetrics and gynaecology at Federal Medical Centre, Owo from } 2010 \text { to } 2015 \text { following } \\
\text { which he was awarded the the fellowship of the West African College of Surgeons (FWACS) } \\
\text { by the West African College of Surgeons in 2015. Presently works as a Consultant in Obstetrics } \\
\text { and Gynaecology at the University of Medical Sciences Teaching Hospital Complex, Akure } \\
\text { Unit, Akure Omdo State Nigeria. He has authored and published a couple of research articles } \\
\text { in both local and international journals }\end{array}$ \\
\hline
\end{tabular}

